\title{
SEM TEMPO PARA BRINCAR: AS CRIANÇAS, OS ADULTOS E A TIRANIA DOS RELÓGIOS ${ }^{1}$
}

DOI105902/0102830817995

Ensaio Convidado

\author{
Roselaine Kuhn \\ Universidade Federal de Sergipe \\ roselainek@yahoo.com.br \\ António Camilo Cunha \\ Instituto de Educação da Universidade do Minho \\ camilo@ie.uminho.pt \\ Andrize Ramires Costa \\ Universidade do Vale do Itajaí \\ andrize.costa@gmail.com
}

\begin{abstract}
Resumo
Qual é o tempo destinado às brincadeiras das crianças na escola? Faz sentido ter thora certaò para brincar? De um lado temos o tempo cronometrado, medido, regulado pela opressão dos relógios dos adultos,concebido pela objetividade dos números, dos calendários, horários e rotinas, representante do mundo pensado (racionalizado). De outro, o tempo sentido e percebido pelas crianças, a subjetividade, a experiência e o acontecimento, representantes do mundo vivido (fenomenológico). A discussãodemarcaas consequências devastadoras no brincar das crianças que frequentam escolas que aspiram ser produtivas através do culto à velocidade, desrespeitando as singularidades da corporeidade e da dimensão lúdica.
\end{abstract}

Palavras-chave: Tempo. Brincar. Fenomenologia. Racionalidade.

\footnotetext{
${ }^{1}$ Ensaio produzido no Doutoramento em Estudos da Criança em andamento no Instituto de Educação da UMINHO; financiado pela CAPES ï Brasil (Coordenação de Aperfeiçoamento de Pessoal de Nível Superior - Brasil).
} 


\section{INTRODUÇÃO}

O que é o tempo? Qual é o tempo das crianças? Como é que as crianças ocupam o seu tempo nas brincadeiras e na escola? Como é que as crianças sentem e percebem o tempo? Faz sentido para a criança ter f̂nora certaòpara brincar? Porque razão os adultos determinam o momento apropriado de ir ao pátio ou ao parque para brincar? Essas perguntas nos inquietam e configuram uma dicotomia: o tempo regulado, cronometrado, coercitivo e medido pelos relógios e o tempo fenomenológico.

Os conceitos de tempo para os antigos gregos ${ }^{2}$, se atualizados podem ilustrar o que discutimos: partindo de uma dicotomia evidente, o brincar da criança é tratado em duas perspectivas diferentes de tempo. Assim como na mitologia grega, há, nos dias atuais, uma polarização com relação à experiência dos homens no que diz respeito ao tempo: uma concepção de tempo matematicamente concebido pelo mundo da racionalidade instrumental que convive ao lado de um tempo vivido existencial e fenomenologicamente concebido.

\section{O TEMPO: RAZÃO E EXPERIÊNCIA}

A partir da modernidade, sobretudo da revolução industrial e científica, a experiência e utilização do tempo se bipolariza e brincar passa a ser vivenciado e percebido de modo diferente entre crianças e adultos, o que se acentua na medida em que r̃dois temposòestão em oposição: o tempo de brincar da criança está próximo de um kairós ou aeon, enquanto para os adultos que controlam o tempo das crianças e atuam orientados por uma concepção de tempo cronológico,o concebemcomo o chronos que a todos oprime e enquadra. Isso se deve a uma dicotomia anterior: o mundo racionalizado e o mundo experienciado, o que resulta de um lado,no tempo concebido pela exterioridade, na objetividade e nos números, um tempo prescrito, controlado e representante do mundo pensado (racionalizado); de outro, o mundo da interioridade, substantivado e espiritualizado na subjetividade, na experiência vivida, na expressão fenomenológica,

\footnotetext{
${ }^{2}$ Os gregos antigos convocaram os mitos para dar um entendimento ao tempo. Para tal, forjaram três conceitos para: Chronos, Kairós e Aeon. O Chronosé o tempo cronológico, sequencial e linear que pode ser medido. Surge no princípio dos tempos formado por si mesmo e que designa a continuidade de um tempo sucessivo; é a soma do passado, presente e futuro. Kairós refere-se a um momento indeterminado em que algo especial acontece: um tempo existencial no qual os gregos acreditavam para enfrentar o cruel e tirano Chronos. Kairós significa medida, proporção, momento crítico, temporada, oportunidade. Aeon é um tempo sagrado e eterno, sem uma medida precisa, um tempo da criatividade onde as horas não passam cronologicamente: é a intensidade do tempo da vida humana, um destino, uma duração, uma temporalidade não numerável nem sucessiva, mas intensiva. Enquanto Chronos é de natureza quantitativa, Kairós e Aeon possuem uma natureza qualitativa. Uma das representações de Chronos é a de um homem que devora o seu próprio filho, num ato de canibalismo não muito difícil de compreender na atualidade. Esta representação deve-se ao fato de os antigos gregos tomarem Chronos como o criador do tempo, logo, de tudo o que existe e possa ser relatado e, uma vez que é impossível fugir do tempo, todos seriam mais cedo ou mais tarde vencidos ou devorados por ele.
} 
representante do mundo vivido (experienciado). A experiência é entendida aqui comoo que nos acontece:

[é ] é o que nos passa, o que nos acontece,o que nos toca. Não o que se passa, não o queacontece, ou o que toca. A cada dia se passam muitascoisas, porém, ao mesmo tempo, quase nada nos acontece.Dir-se-ia que tudo o que se passa está organizadopara que nada nos aconteça. Walter Benjamin [é ] já observava a pobreza de experiênciasque caracteriza o nosso mundo. Nunca se passaramtantas coisas, mas a experiência é cada vez mais rara.(BONDíA, 2002, p. 21).

A razão e os números parecem atrapalhar a busca da verdade, do bem do indivíduo e do mundo experienciado. É neste contexto que emergem os pensadores que criticam a forma rígida e sumária proposta pelos racionalistas: o império das leis da natureza e da lógica, a sobrepujança dos números, a mensurabilidade absoluta dos fenômenos, a generalização por excelência. O elogio fenomenológico, ao ser ontológico, às singularidades, à experiência de cada homem, aos impulsos, emoções, vontades e paixões podem ser as fontes genuínas do conhecimento e da ação: o mundo vivido entendido como ser-no-mundo-em-ação, mundo-experiência, sensível e subjetivo. O mundo vivido é o primeiro, é contemplativo, fenomenológico, surgido antes da ciência, ainda que tenha sido aprisionado por esta.

\section{AS CRIANÇAS E O BRINCAR: OS PRISIONEIROS DO TEMPO}

óDesenvolvemos uma psicologia íntima da velocidade, da economia de tempo e da maximização da eficiência, que se torna mais forte a cada dia que passa.ô

(Guy Claxton apud Honoré, 2005, p. 14)

No brincar, o tempo para a criança é sentido como uma duração em relação a experiência como acontecimento, onde a vivência é marcada pelo prazer da repetição, um eterno recomeço saboroso que ñai e voltaò e nunca acaba. A sensação do tempo é alargada e intensa e não permite à criança que ela tenha préocupação com relação aos instrumentos de medição do tempo mais usuais, como o relógio e o calendário. Então, a percepção da criança sobre o tempo nosacontecimentos é completamente diferente (quiçá, oposta) à dos adultos.

Os adultos têm outra relação com o tempo: estabelecida pelo processo de incorporação das aprendizagens simbolicamente orientadas pela regulação das atividades e por instrumentos utilizados para controlar a vida cheia de compromissos, tratam o brincar de modo pré determinado pelo relógio (e horário) linearmente como uma sucessão de fatos com início e fim. Assim, tendem a cronometrar tudo, determinando o momento que é apropriadoao brincar, como se fosse possívelestipular quando é a hora 
certa para começar e acabar a brincadeira.A ideia de prazer, inconsequência, aventura, sonho, fantasia é posta em segundo plano, em virtude de uma cultura que pressiona pais e educadores a reduzir o tempo de brincar livremente sob o pretexto de prepará-las para a vida adulta, esquecendo-se de que a melhor maneira de aprender se dá brincando. Colocar as crianças em f̂̃ast forwardò é arriscar fazê-las perder seu desejo natural de aprender e aumentar o risco delas se tornarem ansiosas, deprimidas e infelizes. ז̃A infância consiste essencialmente em se fazer descobertas. É um período em que as crianças aprendem sobre si mesmas e sobre suas próprias capacidades. E essas descobertas não ocorrem no contexto de aulas estruturadas(HIRSH-PASEK et al, 2006, p. 12-18).

O tempo sempre foi uma dimensão indissociável da vida escolar, porque a sua estruturação global foi estabelecida por um conjunto de finalidades curriculares e definia a vigência do cenário quotidiano da troca e aquisição de saberes. O tempo subjetivo poderia ser nulo se o interesse impregnasse a gesta da aprendizagem, ou, pelo contrário, denso e imóvel, se o aprender se limitasse a repetir indefinidamente 0 aprendível (FERNANDES, 2008). Faz parte de uma configuração histórica, social e cultural da escola através de inúmeros dispositivos: jornada escolar, ritmo das atividades, horários, diários, rituais, currículo, unidades de ensino, calendários, ciclos, datas marcantes, distribuição das atividades, conteúdos e regulação das relações sociais e pessoais. É, portanto, multidimensional, tem uma identidade própria decorrente da construção simbólica da escola. Está tão enraizado em nossas estruturas mentais na forma de uma regulamentação severa adotada para assegurar o cumprimento das normas que a nossa adaptação a ele foi naturalizada, como se fosse dotado de uma natureza própria e autônoma, sem nos dar conta de que esse cronossistema faz parte de uma estratégia civilizadora em que a escola funciona como um dispositivo resultante do processo acelerado de industrialização e urbanização. O uso racional e rigoroso do tempo na escola repercute em uma concepção de infância, de criança e da própria escola, enquanto um lugar ou sistema meramente produtivo que não parece comportar (ou suportar) outras temporalidades, outros ritmos, mais alongados e consoantes com as horas absorventes. A escola se limita somente à medição mecânica ou digital do tempo(FERNANDES; MIGNOT, 2008).

Consequentemente apressar a infância tem sido uma constante. Desde muito cedo pais e professores maximizam o tempo de modo a promover uma r̃criança organizadaò tendo todos os minutos programados, o que compulsoriamente tem produzido crianças estressadas, deprimidas, fóbicas, ansiosas, esmagadas por mudanças sociais 
desnorteadoras que depositam cada vez mais expectativas no futuro delas, em detrimento do seu presente. Fomentam-se expectativas sensacionalistas com relação à antecipação das capacidades das crianças e a necessidade de forçá-las a alcançarem cada vez mais cedo a aquisição de determinadas habilidades, principalmente cognitivas e esportivas. $\mathrm{Na}$ atualidade elas dispõem de agendas super lotadas, as séries são inflacionadas e a alfabetização tem sido antecipada para o período entre os zero e seis anos(HIRSHPASEK et al, 2006).

\section{O TEMPO COMO CATEGORIA ANTROPOLÓGICA E SOCIOLÓGICA}

A necessidade de medir o tempo a partir da era moderna surge num impulso coletivo para a diferenciação e uma integração crescente somados a um fenômeno complexo de autorregulação e sensibilização em relação ao tempo, através de instrumentos que passam a exercer uma coerção que se presta eminentemente para suscitar o desenvolvimento de uma autodisciplina nos indivíduos, sob uma pressão relativamente discreta, comedida, uniforme e r̃desprovidaòde violência, mas que nem por isso é menos onipresente e da qual é impossível de escapar (ELIAS, 1998).

Esse é o resultado de uma forma de comportamento humano que foi forjado pela própria modernidade, que resultou na nossa forma de conviver em sociedade e de controlar nossas vidas, acabando por incidir sobre uma cultura do culto à velocidade,expressão cunhada por Carl Honoré (2005). Se opondo à tirania dos relógios,Honoré (2005) é representante do movimento de nível mundial denominado Slow (Devagar, ou desaceleração) que preconiza um estilo de vida menos apressado e preocupado com a preservação ambiental ecom os impactos da aceleração da vida moderna, propondo formas alternativas de conviver com o tempo quantitativo de modo que este não suplante a qualidade das relações humanas. Os adeptos (desaceleradores) usam a palavra alemã eigenzeit para resumir suas convicções: Eigen quer dizer próprio e Zeit,tempo. Afirmam que todo o ser vivo, acontecimento, processo e objeto tem o seu próprio ritmo e andamento particulares, o tempo giusto(HONORÉ, 2005, p. 52).

Há muito pouco tempo que o relógio passou a desempenhar um papel importante nos mais diversos fenômenos humanos ou na totalidade da vida do homem moderno. Para Elias (1998), os m̃mistériosò em torno do tempo se acentuam na forma de algumas interrogações: Que os relógios sejam instrumentos construídos e utilizados pelos homens em função das exigências de sua vida comunitária, é fácil de entender. Mas que o tempo tenha igualmente um caráter instrumental, é algo que não se entende com facilidade.As reflexões de Elias (1998) se empenham em reconhecer que o saber resulta de um longo 
processo de aprendizagem e todo indivíduo, por maior que seja a sua contribuição criadora, constrói o conhecimento a partir de um patrimônio de saber já adquirido que contribui para aumentar e isso não é diferente no que concerne ao conhecimento do tempo. Afirmamos que o mesmo mistério ronda os estudos sobre o universo do brincar das crianças pequenas: será o brincar e a brincadeira uma atividade imanente à condição humana? Será o brincar aprendido? Será ontológico ou ontogenético?

Da criação dos relógios como meio de orientação e da generalização do seu uso, surge uma questão que, refletida com base no estilo de vida das pessoas em nossa sociedade, tem se tornado cada vez mais proeminente: o tempo está tão enraizado na nossa consciência, que parece materializar-se a ponto de ser possível tocá-lo. Temos a impressão que o tempo passa, quando na verdade o que nos acontece é o transcorrer das nossas vidas.

\section{A EMERGÊNCIA DOS RELÓGIOS E O BRINCAR}

Nós educadores compreendemos certa necessidade de organização racional, disciplinarização e regulação do tempo para que possamos coexistir na escola (e há quem afirme a necessidade da sua administração rigorosa como meio disciplinador de hábitos), com o intuito de educarmos as crianças pequenas e compartilharmos espaços harmoniosamente. O problema está exatamente no uso implacável do relógio como uma espécie de deus a quem devemos obediência incondicional, como se todas atividades e modos de sentir, pensar e agir pudessem ser cronometrados. Essa é mais uma pretensão de ajustar a criança ao mundo produtivo, seja através do constrangimento do tempo de brincar oupela supressão da liberdade. Mas na verdade,ñA brincadeira é uma atitude fundamental e facilmente perdível, pois requer total inocência. Chamamos de brincadeira qualquer atividade humana praticada em inocência, isto é, qualquer atividade realizada no presente e com atenção voltada para ela própria e não para seus resultadosò (MATURANA; VERDEN-ZÖLLER, 2004, p. 231).

Situando o tempo cronometrado em oposição ao tempo percebido pela criança, o tema perpassa um profundo paradoxo que a própria reflexão exige: duas posições diametralmente opostas em torno do tempo articuladas com o fenômeno do brincar. $\mathrm{O}$ tempo como um dado objetivo do mundo criado, portanto passível de quantificação, medição e aferição exata não se distingue dos demais objetos da natureza, exceto por não ser percebido pelos sentidos corporais. Assim, perguntamos: quem ou o que determina a duração da brincadeira? É o tempo prédeterminado pelo relógio dos adultos? É o sentimento de duração da criança com relação aos acontecimentos? É a percepção 
que a criança tem em relação a brincadeira? Enfim, é o tempo objetivo ou o subjetivo que regula a brincadeira?

Não é possível responder a todas essas questões. No entanto, situar a ação de brincar em relação ao elemento que mais o restringe e o aprisiona, pode ajudar a compreender sobre como temos lidado com essa questão na escola, de modo mais aproximado, como as crianças produzem e promovem suas experiências e porque é importante brincar e se movimentar em liberdade, sem constrangimentose delimitação incondicional do tempo por parte dos educadores ou de outras exigências da ordem da produtividade.

Atualmente, embora exista um hiato entre a literatura e a prática pedagógica, há indícios de que o tempo vivenciado pelas crianças a partir do seu ritmo próprio talvez seja o mais adequado às aprendizagens escolares e no entendimento de vários autores ré socar informação nas crianças com a maior velocidade possível tem valor tão nutritivo quanto engolir um Big Mac. Muito melhor é estudar num ritmo tranquilo, procurando explorar com mais profundidade os temas, estabelecer conexões, aprender a pensar e não apenas a passar nos exames. [é ] aprender Devagar pode abrir horizontes e revigorar a menteò Se não educássemos as crianças a ficar obcecadas com a velocidade, com provas, metas e prazos, as crianças teriam liberdade de se apaixonar pelo aprendizado (HONORÉ, 2005, p. 289). No clássico Emile, Rosseau escreveu: ñA criança tem seu próprio modo de ver, pensar e sentir, e nada é mais insensato do que tentar substituí-lo pelo nossoò (apudHIRSH-PASEKet al, 2006, p. 6). Portanto a Educação Infantil deveria ser um lugar destinado para brincar e desenvolver relações afetivas com os pares. ñQuando apressamos a aprendizagem, frequentemente tentamos ensinar coisas que fazem pouco sentido para a criança e que seriam melhor aprendidas num estágio posteriorò(HIRSH-PASEK et al,2006, p. 36).

Ao redor de todo mundo há uma tendência para que as crianças busquem o conhecimento por si mesmas, livres da obsessão promovida pela correria cronológica, da pressão das provas e exames, das grades curriculares que aprisionam e sufocam a curiosidade e o exercício permanente da dúvida, com mais liberdade para o pensamento criativo, o que tem apontado na direção de um ensino mais agradável e prazeroso. Isso implica livrar da obrigação, do sofrimento, do pânico, do esgotamento e do cansaço promovidos pela aceleração dos ritmos naturais. Outrossim, os ritmos mais suaves e a exploração do mundo da Arte, tem ganhado cada vez mais espaço na educação de crianças pequenas, promovendo a expressão, a comunicação, as linguagens e, 
sobretudo, o diálogo que a criança necessita para inserir-se enquanto sujeito que quer e sabe como conversar com o mundo através da imaginação e da fantasia.

$\mathrm{Na}$ contramão, sequestramos o tempo subjetivo das crianças quando as obrigamos coercitivamente a sucumbir diante da tirania do Chronos,furtamos possibilidades de relações interpessoais significativas, de conhecer o meio e a natureza ao seu redor e de fortalecer uma relação ecológica com o território, resultando na ausência de consciência com relação a biodiversidade e uma visão desintegrada entre passado (história e memória) presente (intensidade e responsabilidade) e futuro (como perseverança consequente de nossa responsabilidade no momento atual, através da projeção de ações refletidas e articuladas com calma) (FRANCESCH, 2011, p. 51).

Então, porque razão cada vez mais se torna frequente a determinação do tempo específico para brincar, sendo rigorosamente administrado e espremido entre momentos destinados a se trabalhar? Como exemplo, destacamos o recreio situado entre dois momentos cansativos e estafantes, servindo apenas para recuperar as forças e a energia que esgota o corpo da criança durante as aulas: o recreio nãoé destinado para brincar mas para descansar e revitalizar; não vale por si mesmo enquanto hora rappropriadaòpara brincar, mas válido para o trabalho escolar, o que corresponde às teorias funcionalistas e suas demandas da cultura escolar. Desse modo, o brincar na escola parece encontrar-se sempre em um tempo que não é para ser vivido plenamente, porque ele está sempre a serviço de algo que é mais importante: produzir e restabelecer.

Reconhecidamenteo livre brincar não é fundamental na escola de crianças. É instrumental assim como o tempo destinado para tal. Não é importante por ele mesmo: somente se torna importante quando ganha um caráter pedagógico e funcional. As crianças aprendem desde cedo que além da hora do recreio há outros tempos apropriados e residuais para tal:o final de semana,as férias e assim por diante, até se chegar ao final de uma vida inteira de contribuição com a esfera do trabalho quandopodemos nos aposentar e, teoricamente, ter ñodo o tempoòpara o ócio e o lazer.

Para Sarmento (2004), [̃...] as culturas da infância possuem, antes de mais, dimensões relacionais, constituem-se nas interações de pares das crianças com os adultos, estruturando-se nessas relações formas e conteúdos representacionais distintos. As culturas da infância exprimem a cultura societal em que se inserem, mas fazem-no de modo distinto das culturas adultas, ao mesmo tempo em que veiculam formas especificamente infantis de inteligibilidade, representação e simbolização do mundo.òUm desses traços distintivos é a temporalidade recursiva, onde o passado tem um significado autônomo, elaborado por um processo de referenciação e significação próprios, em que o 
rẽra uma vezò é sempre a vez em que é anunciado, o que denota uma diferenciação semântica no sentido de passado, presente e futuro.

De um lado, a criança tem uma sensação mais densa, alongadae fluida do tempo que se dilui e se mistura com o seu reuò no ato de brincar e, de outro, há uma necessidade quase não interrogada dos adultos ignorarem a percepção subjetiva da criança. Os adultos administram tudo que a criança faz em função de uma objetividade quantificável imposta pelo cronômetro. Como sinônimo de exatidão, disciplina e organização, o chronos invade as formas mais particulares das crianças se relacionarem com a vida. O caráter instrumental do tempo exerce uma profunda pressão sobre o brincar entre as crianças e talvez nada disso condiga com a natureza e especificidade do brincar, principalmente entre as crianças menores que por excelência brincam com o tempo.

As crianças estão submetidas a uma disciplina e coerção anteriormente desconhecida, em nome das exigências que lhes são impostas em virtude do cumprimento de atividades que dependem do rendimento, determinadas por necessidades práticas que remetem não ao reuòde cada indivíduo, mas ao reuòdo grupo que tem que resolver o problema de determinação do tempo. Essa éuma condição artificial, pois terminar uma tarefa no tempo determinado não respeita o reuòdo sujeito e não garante a responsabilidade do reuòdo grupo, pois em nada afeta ao grupo se reuò não terminar a tarefa, a não ser como solução encontrada para que todos acabem as tarefas ao mesmo tempo e se mantenham o tempo todo ocupados. A padronização das atividades dá ñmenos trabalhoò mas não há uma imbricação social e científica entre as atividades numa sala de aula que justifique o ajuste e administração do tempo de modo padronizado e uniforme e, portanto, o rigor no início e término das tarefas cronometricamente. Portanto a necessidade sem critérios da determinação e sincronização ativa do tempo atende somente a medidas disciplinadoras que desrespeitam o ritmo próprio de cada sujeito.

Para atender esse tipo de demanda convencionamos pensar rápido, analiticamente e logicamente, em consonância com o tique-taque dos relógios no intuito de obter um mundo estruturado, manipulando as probabilidades e tornando alguns eventos mais prováveis do que outros, obtendo ñsoluções claras para problemas bem definidosò Assim reprimimos a intuição, a criatividade e tudo que permita r̃ue as ideias vicejem em seu próprio ritmo no quintal de nossa menteò(HONORÉ, 2005, p. 142-143).

Sempre que se fala da necessidade de desaceleração para as crianças, as brincadeiras são uma das primeiras preocupações. Muitos estudos demonstram 
que a disponibilidade de tempo não organizado para brincar ajuda as crianças menores a desenvolver suas capacitações sociais e de linguagem, a criatividade e a capacidade de aprender. As brincadeiras improvisadas são o oposto do đempo de qualidadeô que implica diligência, planejamento, horários e finalidades. Não estamos falando de aulas de balé nem de jogo de futebol. A brincadeira não organizada se expressa em atividades como cavar a terra no jardim em busca de lesmas, fazer bagunça com os brinquedos no quarto, construir castelos de Lego, correr para baixo e para cima com outras crianças no playground ou simplesmente ficar olhando pela janela. É uma questão de explorar o mundo e a reação que se tem diante dele, no ritmo de cada um. Para um adulto acostumado ao aproveitamento neurótico de cada segundo, brincar improvisadamente parece uma perda de tempo. E nosso primeiro reflexo é encher os espaços áaziosôda agenda com atividades.(HONORÉ, 2005, p. 300).

Por conseguinte, a coordenação das atividades das crianças como se fosse um ciclo contínuo interdependente não faz o menor sentido. O que faz sentido é respeitar o ritmo de crescimento de cada criança que se preocupa com o aqui e agora, porque elas vivenciam intensamente no presente o que fazem sem se preocupar com os resultados, com liberdade e prazer e não por imposição ou obrigação.

\section{CONSIDERAÇÕES FINAIS: TEMPORALIDADES (IM)POSSÍVEIS}

Confirmamos a existência de um tempo que transita na esfera existencial entre o objetivo (matemático) e o subjetivo (sentido, percebido, vivido). Para a criança, o tempo reflete um sentimento de duração menos aparente, não quantificável, não objetivado como resultado, enquanto na realidade física e para os adultos o tempo é matematicamente concebido como uma experiência passível de ser verificada e quantificada.

O modo como os adultos impõem as restrições da ordem do tempo no conjunto das atividades das crianças como regularidades linearesacaba sendo digerido pelas crianças, porque os adultos atuam como reguladores do início e fim de suas atividades e isso tem consequências imediatas na experiência social e cultural dos sujeitos-brincantes e nos diálogos que estabelecem nas suas interações com o mundo, com os outros e consigo mesmos, in(corpo)rando existencialmente o resultado dessa imposição adultocêntrica. Vivenciar o tempo pré definido pelo outro, pura e simplesmente para determinar a ação do reuò representa a opressão simbólica a que todos estamos submetidos em relação aos usos do tempo em nossa sociedade contemporânea pós industrial. 
Isso pode nos ajudar a compreender a questão da futurização ${ }^{3}$ da criança tão intensamente difundida: aos olhos dos adultos a criança mão é aqui e agoraò mas será rälguémòsomente quando crescer, quando for r̃gente grandeòe produtiva. Assim, não se pode permitir que ela seja o que deseja e se a trata como um adulto em miniatura adultizando-a antecipadamente, projetando o que ela deverá ser: um adulto produtivo.Então se antecipam as suas pré ocupações no intuito de qualificá-la para ser. Não é à toa que é comum se perguntar às crianças o que elas querem ser quando crescer.

Portanto, é necessário compreendermos os abusos que se cometem na relação de poder que se instaura entre adultos e crianças: os primeiros se autointitulam no direito de restringir o tempo de duração da brincadeira dos pequenos e, até mesmo, suprimindo esse tempo (como castigo, por exemplo) ou colocando-o numa dimensão residual e exígua. A criança tem direito à liberdade de brincar e se movimentar sem constrangimentos deixando fluir plenamente a imaginação, a fantasia, o prazer, a repetição, a criatividade, a alegria a seu modo, orientada pelas suas formas particulares de lidar com essa linguagem que é original e singular na infância.

A natureza ainda continua ser tratada como a própria encarnação da ordem enquanto a sociedade humana (e as crianças a serem r̃ civilizadasò) parece caótica, desordenada, indisciplinada, desorganizada:

Meninos de seis anos de idade organizam sua vida social pelo celular [é ]. A própria infância parece estar sendo encurtada [é ]. Os jovens de hoje certamente são mais ocupados, mais programados e mais apressados que os da minha geração. [é ] As crianças não nascem obcecadas com velocidade e produtividade ï nós é que as fizemos assim. [é ]. Na escola, aprendem a viver olhando para o relógio e a empregar o tempo da maneira mais eficiente possível. Os pais ainda reforçam a tendência, tratando de encher a agenda dos filhos com atividades extracurriculares. De todas as maneiras, as crianças estão sempre recebendo a mensagem de que menos não é mais e de que é sempre melhor fazer tudo mais depressa. (HONORÉ, 2005, p. 281-283).

Hirsh-Pasek (et al2006) concluem que o aprendizado precoce e a aceleração acadêmica em nada contribuem para o desenvolvimento cerebral das crianças. Ao contrário, as autoras asseveram que é mito a ideia de que as crianças devem raproveitar ao máximo o tempo para obterem bons resultadosòe constatam que as crianças que são aceleradas e pressionadas desenvolvem ñpersonalidades menos integradasò demonstrando dificuldade de interagir com os outros. îE a intensificação não se limita à

\footnotetext{
${ }^{3}$ Oaklander (1980)diz: enquanto brinca, a criança procura desesperadamente sobreviver e, para isso, quer apenas o auxílio dos adultos. Ou seja, ñBrincar não tem nada a ver com o futuro. Não é uma preparação para nada, é fazer o que se faz em total aceitação, sem considerações que neguem a sua legitimidade. [é ]. Para aprender a brincar, devemos entrar numa situação na qual não podemos senão atentar para o presenteò (MATURANA; VERDEN-ZÖLLER, 2004, p. 231).
} 
formação escolar. Entre uma aula e outra, muitas crianças correm de uma atividade extracurricular a outra, o que não Ihes deixa tempo para relaxar, brincar livremente ou permitir que a imaginação se solte.ò(HONORÉ, 2005, p. 284-285). Esse fenômeno já tem nome: é a hipereducação. E isso tem tido consequências graves:

As crianças estão pagando um preço cada vez maior por levarem vidas apressadas. Já aos cinco anos de idade podem começar a sofrer de problemas estomacais, enxaqueca, insônia, depressão e distúrbios de alimentação provocados pelo estresse. Como todo mundo em nossa sociedade đ́sempre ligadaô muitas crianças hoje em dia dormem muito pouco. O que pode deixá-las irritadiças, agitadas e impacientes. Crianças que não dormem o suficiente tem mais dificuldade para fazer amigos i e mais possibilidades de ficar abaixo do peso desejável [é ] a dedicação intensiva a um esporte em idade muito precoce pode causar danos físicos e psicológicos. O mesmo se aplica à educação. São cada vez maiores os indícios de que as crianças aprendem melhor quando podem aprender com calma. (HONORÉ, 2005, p.285).

Ao que parece o chronos como referência de um tempo sequencial e linear cristalizou-se como um deus moderno e antropofágico reinventado pelos adultos urbanos das sociedades industrializadas, enquanto as crianças acreditam e veneram outros deuses que se parecem com kairós e aeon. Assim como para kairós e aeon o brincar refere-se a um momento indeterminado que nunca tem hora para começar e muito menos para acabar. A isso Huizinga (2000) designou como o caráter desinteressado do jogo porque essa experiência não carece de uma justificação que seja exterior a ela, interessando somente ao jogador a quem nada mais importa. É um momento em que algo especial acontece, assim como em kairós: é um tempo sagrado e eterno, sem medida precisa, um tempo da criatividade onde as horas não passam. É sagrado porque é ritualístico e absolutamente extraordinário para quem brinca. É quando a vida pulsa fomentada pela magia, onde o onírico pode e acontece. É matéria do imprevisível, do incomunicável, do não dito e do acaso e não se submete a regulação mecânica do tempo, porque é o tempo da fruição.

Talvez essa tenha sido uma das razões pela qual a teogonia órfica colocou ao lado de Chronos uma companheira: Anankeé a inevitabilidade, pois nem mesmo oChronos que aprisiona, pressiona e oprime seja por si só independente da própria casualidade de si mesmo e da vida. Assim, cremos plenamente que há uma premência de discutirmos essa questão no interior da atividade humana menos previsível: o brincar e se movimentar das crianças.

É preciso reconhecer que as crianças não são absolutamente assujeitadaspelas condições radicais que a segunda modernidade Ihes imputa, haja vista que elas realizam processos de significação e estabelecem modos de monitorização das ações que são específicos e genuínos, a exemplo do mundo da fantasia (SARMENTO, 2004). No 
entanto, a nós ainda cabe digerir e compreender como isso arroga efeitos na administração do tempo imposto pelos adultos na direção da criança, entendendo como éressignificado pela criança e qual seria sua representação numa perspectiva relacional, pois a criança nunca brinca só, mesmo quando brinca sozinha.

Se existem condições em que a humanidade adquire seu saber e desenvolve os símbolos sociais que funcionam como instrumentos de orientação e regulação do tempo, cabe à escola, como instituição que promove a construção e difusão dos saberes, não coagir sobre os sujeitos aprendentes de modo a naturalizar a coerção do relógio: à escola também interessa problematizar as transformações da humanidade perante os objetos simbólicos do saber.

Portanto, refletir sobre a coação do tempo sobre o fenômeno do brincar na Educação Infantil é premente. A escola é uma agência de veiculação dos símbolos sociais e não pode operar com os mesmos sentidos que oprimem os saberes e fazeres da criança. A tirania do tempo cronometrado não pode ser naturalizada, funcionando como mera condicionante sócio simbólica indiferente aos desejos e interesses da criança e restringindo a liberdade, sobretudo porque a criança é o sujeito do saber na escola. Para tanto, podemos promover o tempo da liberdade e da espontaneidade para que as crianças dialoguem com sua sensibilidade e intuição livremente e, por consequência, vivenciem a sua humanidade naturalmente e autonomamente.

Muitas experiências escolares inovadoras tem refletido sobre o tempo que aprisiona e o culto à velocidade, na expectativa de livrar as novas gerações da epidemia do tempo racionalizado. Mas, para isso, talvez seja preciso reinventar a filosofia da infância, assim como fizeram os românticos há pouco mais de dois séculos atrás. Reinventar o conceito de infância forjado pela modernidade diz respeito à considerar a autoria participativa da criança enquanto sujeito que sente, age, pensa, sabe e é capaz de contribuir no processo de tomada de decisões, o que implica em ambientes escolares menos fragmentados, com mais liberdade, fluidez e ênfase no prazer de aprender e estudar, sem afobação, sem que os relógios governem nossas vidas, com mais tempo e espaço para as brincadeiras livres não organizadas e mediadas pelos adultos, com menos obsessão de aproveitar cada segundo, menos pressão para que as crianças imitem os hábitos dos adultos e, sobretudo, olhando mais para o presente do que para o futuro, aproveitando melhor a vida que se apresenta na forma de vivências e experiências do aqui e agora, o que as crianças sabem muito bem fazer (HONORÉ, 2005, p. 306-308).

É urgente repensar o tempo educativo não somente em sua vertente organizativa e técnica mas ética e profundamente humana, baseada em uma concepção respeitosa com 
os ritmos da infância garantindo o crescimento harmônico e equilibrado,tendo em conta razão e emoção, mente e espírito e não somente convicções quantitativas, aceleradas e mercantilistas pois, pela sua natureza, a educação é lenta enecessita de paciência e tranquilidade (FRANCESCH, 2011, p. 9-13).

$\mathrm{Na}$ educação desacelerada, a lentidão tem mais sentido e os conceitos são mais permanentes, duram toda a vida: m̃mais, antes e mais rápido não são sinônimos de melhorò (HONORÉ, 2005). Devolver o ritmo adequado às aprendizagens é uma necessidade: porque que queimar etapas se sabemos que desse modo o que conseguimos fazer são apenas aprendizagens superficiais que se esvaem assim que forem utilizadas? Porque currículos exaustivos e aprendizagens feitas antes do tempo? A escola da lentidão dá importância às aprendizagens feitas com profundidade e às experiências reais das crianças (FRANCESCH, 2011, p. 14).

Por fim, é imprescindível refletir e agir sobre esse impulso que temos dado na direção quase inconsciente de submergir no culto à velocidade, quando os templos e deuses não mais são mitológicos, mas estão materializados entre nós na forma de instrumentos de medição do tempo que nos convocam ao império da quantidade em detrimento da qualidade. Justamente porque a qualidade é aquela que necessita que o tempo seja ñ tempo de viverò principalmente quando falamos das crianças pequenas: r̃ Onsiderando a forma peculiar como a criança concebe o seu viver ï com a atenção para o momento presente de sua vida e sem esperar por resultadosò (KUNZ; STAVISKI; SURDI, 2013).

Talvez o caminho seja o de deixar as crianças viver plenamente o seu tempo de ser criança e, ao invés de oprimi-las e tentar ensiná-las, deveríamos amá-las e escutá-las mais.

\section{REFERÊNCIAS}

BONDÍA, Jorge Larrosa. Notas sobre a experiência e o saber de experiência. Revista Brasileira de Educação. Campinas: Unicamp, n. 19, 2002.

ELIAS, Norbert. Sobre o tempo.Rio de Janeiro: Jorge Zahar Editor, 1998.

FERNANDES, Rogério; MIGNOT, Ana Chrystina V. (Orgs.) $O$ tempo na escola. Porto: Profedições, Ida, 2008.

FERNANDES, Rogério. A borboleta e o tempo escolar.In:O tempo na escola.Porto: Profedições, Ida, 2008, p. 17-31. 
FRANCESCH, Joan Doménech. Elogio de la educación lenta.Barcelona: Graó, 2011.

HIRSH-PASEK, Kathryn; GOLINKOFF, Roberta Michnick; EYER, Diane. Einstein teve tempo para brincar: Como nossos filhos realmente aprendem e por que eles precisam brincar.Rio de Janeiro: Guarda-Chuva, 2006.

HONORÉ, Carl. Devagar. Rio de Janeiro: Record, 2005.

HUIZINGA, Johan. Homo ludens. São Paulo: Perspectiva, 2000.

KUNZ, Elenor; STAVISKI, Gilmar; SURDI, Aguinaldo. Sem tempo de ser criança: a pressa nocontexto da educação de crianças e implicações nas aulas de Educação Física.Revista Brasileira de Ciências do Esporte.Florianópolis, v. 35, n. 1,p. 113-128, 2013.

MATURANA, Humberto;VERDEN-ZÖLLER, Gerda. Amar e brincar: Fundamentos esquecidos do humano - do patriarcado à democracia.São Paulo: Palas Athena, 2004.

OAKLANDER,Violet. Descobrindo crianças: A abordagem gestáltica com crianças e adolescentes. São Paulo: Summus, 1980.

SARMENTO, Manuel Jacinto. As culturas da infância nas encruzilhadas da $2^{a}$ modernidade, In: Sarmento, Manuel \& Ana Beatriz, Cerisara. (Orgs.).Crianças e miúdos: Perspectivas sociopedagógicas sobre a infância e educação.Porto: Asa, 2004. p. 934.

NO TIME TO GAMES: THE CHILDREN, THE ADULTS AND TIRANY OF THE CLOCKS

\begin{abstract}
What's the time for the games of children in school? It makes sense to have "the right time" to play? On the one hand we have the measured time, regulated by the oppression of adult watches, designed by the objectivity of numbers, calendars, schedules and routines, representative of the thinking world (rationalized). On the other, the time felt and perceived by children, subjectivity, the experience and the event, representatives of the lived world (phenomenological). The discussion marks the devastating consequences in the play of children attending schools that aspire to be productive through the cult of speed, disregarding the singularities of corporeality and playful dimension.
\end{abstract}

Key-words: Time. Play. Phenomenology. Rationality. 


\section{SIN TIEMPO PARA JUGAR: LOS NIÑOS, LOS ADULTOS Y LA TIRANIA DE LOS RELOJES}

\section{RESUMEN}

¿Cuál es el tiempo para los juegos de los niños en la escuela? ¿Tiene sentido tener "el momento adecuado" para jugar? Por un lado tenemos el tiempo cronometrado, medido, gobernado por la opresión de los relojes adultos, diseñados por la objetividad de los números, calendarios, horarios y rutinas, representante del mundo de pensamiento (racionalizado). Por otro, el tiempo sentía y percibido por los niños, la subjetividad, la experiencia y el evento, representantes del mundo vivido (fenomenológico). El debate marca las consecuencias devastadoras en el juego de los niños que asisten a escuelas que aspiran a ser productivas a través del culto a la velocidad, sin tener en cuenta las singularidades de la corporalidad y la dimensión lúdica.

Palabras-clave: El tiempo. El juego. La fenomenología. La racionalidad. 